\title{
Screening Common Bean for Resistance to Four Sclerotinia sclerotiorum Isolates Collected in Northern Spain
}

\author{
Aida Pascual, Ana Campa, and Elena Pérez-Vega, Área de Cultivos Hortofrutícolas y Forestales, Servicio Regional \\ de Investigación y Desarrollo Agroalimentario (SERIDA), 33300, Villaviciosa, Asturias, Spain; Ramón Giraldez, \\ Department of Biología Funcional, University of Oviedo, 33006 Oviedo, Asturias, Spain; Phillip N. Miklas, USDA- \\ ARS, Vegetable and Forage Crops Research Unit, 24106 N. Bunn Rd., Prosser, WA 99350; and Juan José Ferreira, \\ Área de Cultivos Hortofrutícolas y Forestales, SERIDA, Spain
}

\begin{abstract}
Pascual, A., Campa, A., Pérez-Vega, E., Giraldez, R., Miklas, P. N., and Ferreira, J. J. 2010. Screening common bean for resistance to four Sclerotinia sclerotiorum isolates collected in northern Spain. Plant Dis. 94:885-890.

White mold, caused by the fungus Sclerotinia sclerotiorum, is a serious disease in common bean (Phaseolus vulgaris) causing significant yield loss. Few cultivars with high levels of physiological resistance to white mold have been described in common bean. The objectives of this study were to (i) determine variation in aggressiveness for the local $S$. sclerotiorum isolates and (ii) identify sources of resistance against local isolates using the greenhouse straw test. The evaluated materials included 199 accessions of a core collection established from the main bean gene bank in Spain and 29 known cultivars or lines, 5 of them described as resistant sources to white mold: G122, PC50, A195, Cornell 606, and MO162. Significant differences for aggressiveness among the four $S$. sclerotiorum isolates were detected. Generally, isolates 1 and 3 were more aggressive than isolates 2 and 4 . In all, 19 genotypes exhibited a level of resistance equal to or significantly better than G122: 11 accessions from the core collection and 8 cultivars or lines from known materials, including the lines A195 and Cornell 606. To confirm resistance, 19 selected genotypes were tested using a more severe straw test with reactions evaluated 21 days after inoculation. Fifteen genotypes exhibited significantly less susceptibility than G122: eight accessions from the core collection and the known cultivars or lines AB136, Kaboon, BRB57, BRB130, Don Timoteo, and A195. The logical next step will be to evaluate the best genotypes for field reaction to white mold and conduct inheritance studies.
\end{abstract}

White mold, caused by the fungus Sclerotinia sclerotiorum (Lib.) de Bary, is a serious disease in common bean (Phaseolus vulgaris L.) causing significant yield loss, particularly in temperate and humid production regions worldwide. In northern Spain, S. sclerotiorum is endemic and causes major white mold disease problems for beans produced in the region. Several agronomic strategies such as crop rotation, use of pathogen-free seed, fungicide application, plant spacing, row direction, mulching, or weed control $(7,29)$ have been indicated to control this disease. Integration of such strategies helps to reduce disease severity. The use of resistant bean cultivars is recommended to enhance effectiveness of integrated white mold control strategies.

Corresponding author: J. J. Ferreira
E-mail: jjferreira@ serida.org

A. Pascual and A. Campa contributed equally to this work.

Accepted for publication 13 March 2010.

doi:10.1094/PDIS-94-7-0885

(C) 2010 The American Phytopathological Society
Resistance against this pathogen in common bean is complex, conditioned by both avoidance and physiological mechanisms (14,16). Avoidance mechanisms, which generate conditions limiting infection and disease progress, include morphological traits related to plant architecture and phenological traits (9). Characteristics such as erect and open plant structure, less dense canopies, elevated pod set, reduced lodging, and early maturity contribute to reduced white mold damage $(9,26)$. For physiological resistance, plant defense mechanisms inhibit infection or spread of the pathogen in host tissues. Both avoidance and physiological resistance are quantitatively inherited. Miklas et al. (19) generated a comprehensive linkage map of quantitative trait loci (QTL) conditioning resistance to white mold. They located 38 QTL that coalesced into 22 regions across nine linkage groups. Major QTL on linkage groups 2,7 , and 8 have been validated in markerassisted selection studies $(1,3,18)$.

Few cultivars with high levels of physiological resistance to white mold have been described in common bean. Many breeding programs and genetic analyses have been based on resistant sources such as 'ICA Bunsi', G122, NY6020-4, or PC-50
$(14,17,21,26)$. With the exception of ICA Bunsi, most genotypes with high resistance levels against white mold appear to derive from the Andean gene pool (13), one of the two major germplasm groups identified in wild and cultivated common bean materials (5). The majority of the local germplasm collected in the Iberian Peninsula has been classified as Andean $(22,25)$. Therefore, bean collections maintaining local germplasm from this area represent an opportunity for identifying new resistant sources with specific utility for developing cultivars with improved white mold resistance for the region.

Screening for resistance to $S$. sclerotiorum in the field is complicated by interaction of avoidance and physiological resistance mechanisms. Laboratory and greenhouse screening methods are used solely to detect physiological resistance. The straw test (23) is the most widely used greenhouse screening method (2). Straw test results correlate well with field tests $(1,11)$ and have been used to identify resistant accessions in collections (13). The straw test is currently being used to select white-mold-resistant lines in plant breeding programs $(18,28,31)$ and has identified many QTL associated with physiological resistance (11,21). In general, possible pathogen variation has not been considered in these studies.

To initiate a breeding program for resistance to a pathogen, knowledge about pathogenic variation as well as identification of different resistant sources is warranted. The objectives of this study were to (i) determinate the possible variation in aggressiveness of the local S. sclerotiorum isolates causing white mold in common bean and (ii) identify potential sources of resistance against local isolates. This information will be of interest to regional plant breeding programs focused on increasing levels of white mold resistance for local common bean market classes. Novel sources of resistance, if identified in this study, could have significance for white mold resistance breeding programs worldwide.

\section{MATERIALS AND METHODS}

S. sclerotiorum isolates. In total, 12 isolates were obtained from naturally infected 
bean plants collected in northern Spain. Each isolate was derived from a sclerotium and a unique hyphal tip. Evaluations were carried out with four isolates that were selected based on previously determined mycelia compatibility reactions and geographic origin (Table 1). Each isolate represented a distinct mycelial compatibility group based on incompatible mycelial reactions for all paired comparisons between the isolates, conducted according to Kull et al. (10). Sclerotia of the four isolates were maintained at $-20^{\circ} \mathrm{C}$. The sclerotia were germinated on potato agar dextrose medium (Difco, Becton, Dickinson and Company, Spark, MD) in a standard petri plate and then subcultured to prepare plates of fresh, actively growing mycelium for the inoculations.

Plant material. In all, 228 bean materials maintained at the Servicio Regional de Investigación y Desarrollo Agroalimentario collection (Villaviciosa, Asturias, Spain) were evaluated for reaction to $S$. sclerotiorum isolates from northern Spain. The evaluated materials included 199 accessions of the core collection established from the main bean gene bank in Spain (22) and 29 well-known cultivars or lines: 10 cultivars used for anthracnose (Colletotrichum lindemuthianum (Sacc. \& Magnus) Briosi \& Cavara) race characterization (Michelite, MDRK, Perry Marrow, Cornell 49 242, Widusa, Kaboon, PI207262, TO, TU, and AB136) (20); 5 lines used as sources resistant to anthracnose (A252, A321, A493, SEL1360, and SEL1308); 4 lines or cultivars used as sources resistant to Bean common mosaic virus (BCMV) and Bean common mosaic necrosis virus (BCMNV) (Don Timoteo, BRB57, BRB130, and IVT7214); 5 lines identified with high or moderate levels of resistance to white mold (A195, G122, Cornell 606, PC 50, and MO 162) $(6,14,21,27,30)$, originally supplied by $\mathrm{S}$. P. Singh (Kimberly Research and Extension, University of Idaho); line A55, a line susceptible to white mold (14); the lines BAT93 and Jalo EEP558, used as parents of a major core mapping population (4); and cvs. Sanilac and Tendergreen, used as references for the two major gene pools, Middle American and Andean, described for the species (5).

Disease reaction. The greenhouse straw test (23) was used to screen the 199 accessions from the Spanish core collection and the 29 known lines in separate experiments. For all experiments, four to five seeds of each material were planted in a $15-\mathrm{cm}$ plastic pot with 1.5 liter of soil mix (containing peat:perlite, 80:20) and Osmocote Exact Standard 3-4M slow-release fertilizer (The Scotts Company, Columbus, $\mathrm{OH})$ at $1 \mathrm{~g} \mathrm{pot}^{-1}$. Plants were watered and additionally fertilized for normal growth. Plants were inoculated when the fourth internode in the main stem was totally developed (21- to 28-day-old plants). Inoculum preparation was as described by Miklas (12). A single mycelial plug inserted within a straw was placed mycelialside down on the cut stem. Inoculated plants were maintained at moderate temperature $\left(18\right.$ to $\left.24^{\circ} \mathrm{C}\right)$ in shade with high relative humidity $(>70 \%)$.

For each material, there were two pots planted per isolate tested. One pot of each material-isolate combination represented a replication. The two replications were arranged in a randomized complete block design (RCBD). Three separate runs consisting of two replications each were conducted. The 29 well-known lines were tested against all four isolates (experiment I) whereas the 199 core accessions were only tested against a single isolate (isolate 2; experiment II). Of the 199 tested core collection accessions, the 11 which exhibited the most resistant reactions were tested again in a separate RCBD with two replications and three separate runs but this time against all four isolates (experiment III). The resistant line G 122 was included for comparison purposes. Evaluations of the core collection accessions were conducted in autumn 2007 whereas accessions with high resistant levels and the 29 known materials were evaluated in spring 2008.

The severity of disease progression, considering invasion of the main stem, was assessed 8 to 10 days after inoculation (short-term evaluation) using a 1-to-9 severity scale (12) where a value of $1=$ no symptoms and $9=$ total plant collapse. $\mathrm{Cv}$. Cornell 49242 was included in each evaluation as a susceptible check because most of these plants had a disease severity score rating of 9 (plant collapse and death) by about 8 days after inoculation. This susceptible check was not included in the data analysis for experiments II, III, or IV.

To confirm resistance of the 11 selected core accessions, they were retested in spring 2009 but, this time, severity was evaluated 21 days after inoculation (longterm evaluation; experiment IV). These 11 accessions were tested along with 8 superior-performing lines taken from the 29 well-known materials tested above. Mock inoculations using just agar were conducted in parallel to assess the effect of the straw test on plant viability and growth in this experiment. A pot with 4 to 5 plants of each tested material was mock inoculated. Experimental design was the same as the short-term evaluation experiments described above. The same 1-to-9 disease severity scale was used to assess plant reaction to white mold infection.

Data analysis. Disease severity score data for each experiment was analyzed by analysis of variance (ANOVA). Runs were considered a random effect and isolates and genotypes fixed effects. With this mixed-effect model, the three-way interaction mean square (MS) was used as the error term (denominator) in the $F$ test for the two-way interactions. The $F$ test for genotype was calculated with: [(genotype MS + three-way (genotype-isolate-run) interaction $\mathrm{MS}) /($ genotype-isolate $\mathrm{MS}+$ genotype-run MS)]. Similarly, the $F$ test for isolate was obtained from [(isolate MS + three-way interaction MS)/(genotypeisolate MS + isolate-run MS)]. For experiment II, the $F$ test for genotype was tested using the two-way interaction (genotype-run) MS as the denominator. Significant differences between means were tested using least significant difference $(5 \%)$. Simple correlations were performed to compare genotype disease ratings between runs and between short- and long-term evaluations. Statistical analyses were carried out using the SPSS V12 software.

\section{RESULTS}

Short-term response of the lines and cultivars. Twenty-nine cultivars or breeding lines were evaluated for white mold against four local $S$. sclerotiorum isolates using the greenhouse straw test. All interactions were significant except isolate-run (Table 2; experiment I). The average correlation among genotypic means (Table 3 ) among the three runs was low $(r=0.088, P$ $<0.05)$, indicating that the genotype-run interaction resulted mainly from magnitude of genotypic response between runs. Significant differences in the response against the four isolates were observed for the majority of the examined genotypes that contributed to the significant genotype-isolate interaction. Isolates 1 and 3 were the most aggressive in this set of materials based on the mean reactions (6.11 and 6.03, respectively) while isolate

Table 1. Origin of the four Sclerotinia sclerotiorum isolates used in this study

\begin{tabular}{|c|c|c|c|c|}
\hline Isolate & Host $^{\mathrm{a}}$ & Market class & Year & Locality \\
\hline 1 & Cv. Xana & Fabada & 2005 & Villaviciosa, Asturias, Spain $\left(43^{\circ} 29^{\prime} 01^{\prime \prime} \mathrm{N} ; 05^{\circ} 26^{\prime} 11^{\prime \prime} \mathrm{W}\right.$; elevation $\left.6.5 \mathrm{~m}\right)$ \\
\hline 2 & Landraces & Flageolet & 2006 & San Tirso de Abres, Asturias, Spain $\left(43^{\circ} 24^{\prime} 47^{\prime \prime} \mathrm{N} ; 07^{\circ} 08^{\prime} 31^{\prime \prime} \mathrm{W}\right.$; elevation $\left.190 \mathrm{~m}\right)$ \\
\hline 3 & Cv. Andecha & Fabada & 2007 & 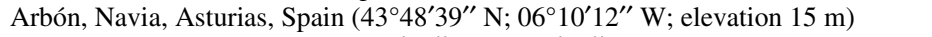 \\
\hline 4 & Cv. Moncau & Hook & 2007 & El Vallés, Barcelona, Spain $\left(41^{\circ} 30^{\prime} 12^{\prime \prime} \mathrm{N} ; 02^{\circ} 09^{\prime} 10^{\prime \prime} \mathrm{W}\right.$; elevation $\left.120 \mathrm{~m}\right)$ \\
\hline
\end{tabular}

a Infected common bean growing in the field from which each isolate was collected. 
4 was the least aggressive (5.25). Among genotypes, six were very susceptible to all four isolates (disease score $>7$ ): Cornell 49 242, A55, TU, SEL1360, A493, and BAT93. Eight genotypes had either partially resistant or intermediate reactions (equal to or better than G122): A195, Don Timoteo, BRB57, JALO EEP 558, AB136, Cornell 606, BRB130, and Kaboon. Cv. Don Timoteo and the line A195 were significantly more resistant than G122. The lines Cornell 606, PC50, and MO162, observed with high levels of resistance in other studies, were susceptible to isolate 1 and exhibited differential responses against the remaining isolates (partial resistance or intermediate reaction). These lines were ruled out as sources of resistance against local isolates.

Short-term response for core collection accessions. The 199 accessions included in the core collection were evaluated against isolate 2. The genotype response to white mold varied between runs, resulting in a significant genotyperun interaction (Table 2; experiment II). The average correlation among genotypic means among the three runs was $r=0.113$ $(\underline{U}<0.001)$. Although significant, the low correlation again suggests that the genotype-run interaction results primarily from differences in the magnitude of genotypic response between the separate runs. The different response between runs may result from sensitivity of the screening method to slight changes in environmental conditions across the greenhouse space used or other factors, such as genetic variation within the accessions themselves. Because of the variability in response from run to run, multiple runs are warranted for characterizing large sets of genotypes for response to white mold using the greenhouse straw test.

Averaged across runs, 11 accessions exhibited partial resistance (disease severity less than 4), 123 had intermediate reaction (disease severity between 4 and 6), and 65 showed a susceptible reaction (Fig. 1). Major morpho-agronomic traits of the 11 accessions classified as resistant to isolate 2 are summarized in Table 4 . The 11 accessions represent nine different seed phenotypes, 6 possess potential culinary use as a snap bean, and all originate from the Andean gene pool (22).

The 11 accessions with a high level of resistance to isolate 2 were evaluated again but, this time, against four isolates. ANOVA did not reveal significant differences for the main effects genotype, isolate, or run or the genotype-isolate interaction (Table 2; experiment III). The average correlation among genotypic means among the three runs was low $(r=0.312, P<$ $0.05)$, indicating once again that multiple runs should be used to evaluate common bean accessions for white mold response using the greenhouse straw test. The 11 accessions showed high levels of resistance to the four isolates (Table 5). Four accessions (BGE003121, BGE003404,
BGE013953, and BGE022494) had a disease score equal to or less than 4 against all four isolates. Accession BGE022494 had the most resistant reaction, albeit not significantly different from the other genotypes. Isolates 1 and 3 were the most aggressive against this set of select resistance materials, as was observed in experiment I.

Long-term response of select materials. In all, 17 genotypes, 11 accessions from the local collection and 6 cultivars or lines (Jalo EEP558 would have been included but seed was unavailable) with the highest levels of resistance (equal to or better than G122) in the previous tests were assessed 21 days post inoculation to further investigate the partially resistant response of these materials to white mold

Table 3. Short-term responses of 29 common bean cultivars or lines inoculated with four Sclerotinia sclerotiorum isolates from northern Spain using the greenhouse straw method (experiment I)

\begin{tabular}{lccccc}
\hline & \multicolumn{5}{c}{ Mean } \\
Genotype & Isolate 1 & Isolate 2 & Isolate 3 & Isolate 4 & Genotype \\
\hline A195 & 3.97 & 3.06 & 4.16 & 3.77 & 3.74 \\
Don Timoteo & 3.89 & 3.76 & 3.79 & 3.85 & 3.82 \\
BRB57 & 4.65 & 4.59 & 4.10 & 3.89 & 4.31 \\
JALO EEP 558 & 5.58 & 3.58 & 3.95 & 4.51 & 4.40 \\
AB136 & 4.36 & 4.45 & 4.89 & 4.26 & 4.49 \\
Cornell 606 & 6.08 & 4.00 & 3.87 & 4.25 & 4.55 \\
G122 & 4.85 & 4.78 & 4.62 & 4.50 & 4.71 \\
BRB130 & 4.65 & 4.97 & 4.77 & 4.84 & 4.81 \\
Kaboon & 4.98 & 5.09 & 5.60 & 4.90 & 5.14 \\
PC 50 & 6.40 & 4.33 & 5.10 & 5.56 & 5.35 \\
Tendergreen & 5.50 & 5.30 & 5.49 & 5.17 & 5.36 \\
P1-207262 & 4.70 & 6.09 & 6.13 & 4.81 & 5.43 \\
MO 162 & 6.28 & 5.33 & 5.56 & 4.93 & 5.52 \\
MDRK & 6.40 & 6.07 & 5.47 & 4.55 & 5.62 \\
SEL1308 & 6.13 & 5.78 & 6.14 & 4.78 & 5.71 \\
Perry Marrow & 6.44 & 5.93 & 5.97 & 4.83 & 5.79 \\
Michelite & 6.12 & 5.70 & 6.73 & 5.17 & 5.93 \\
A252 & 5.93 & 6.65 & 6.36 & 4.83 & 5.94 \\
IVT7214 & 6.95 & 5.30 & 6.51 & 5.01 & 5.94 \\
Widusa & 6.40 & 5.76 & 6.98 & 4.66 & 5.95 \\
Sanilac & 6.45 & 6.12 & 6.55 & 5.01 & 6.03 \\
TO & 6.77 & 6.60 & 6.93 & 5.80 & 6.52 \\
A321 & 6.70 & 6.84 & 7.10 & 6.50 & 6.78 \\
BAT 93 & 7.35 & 7.36 & 7.01 & 6.29 & 7.01 \\
A493 & 7.40 & 7.41 & 6.95 & 7.47 & 7.30 \\
SEL1360 & 8.24 & 7.56 & 7.61 & 6.37 & 7.44 \\
TU & 7.79 & 7.87 & 8.50 & 6.00 & 7.54 \\
A55 & 8.00 & 8.13 & 7.96 & 7.73 & 7.95 \\
Cornell 49 242 & 8.30 & 7.90 & 8.55 & 7.94 & 8.17 \\
Isolate mean & 6.11 & 5.73 & 6.03 & 5.25 & $\ldots$ \\
LSD (0.05) & $\ldots$ & $\ldots$ & $\ldots$ & $\ldots$ & 0.53 \\
\hline
\end{tabular}

${ }^{a}$ Least significant difference value (5\%) for comparing the genotype-isolate means in the table $=0.45$.

Table 2. Analysis of variance results for four experiments which tested response of common bean to Sclerotinia sclerotiorum ${ }^{\mathrm{a}}$

\begin{tabular}{|c|c|c|c|c|c|c|c|c|c|c|c|c|}
\hline \multirow[b]{2}{*}{ Source } & \multicolumn{3}{|c|}{ Experiment I } & \multicolumn{3}{|c|}{ Experiment II } & \multicolumn{3}{|c|}{ Experiment III } & \multicolumn{3}{|c|}{ Experiment IV } \\
\hline & df & MS & $\boldsymbol{F}$ & df & MS & $\boldsymbol{F}$ & df & MS & $F$ & df & MS & $\boldsymbol{F}$ \\
\hline Run & 2 & 4.7 & $1.9 \mathrm{~ns}$ & 2 & 31.5 & $7.3 *$ & 2 & 1.0 & $0.5 \mathrm{~ns}$ & 2 & 19.0 & $3.4 \mathrm{~ns}$ \\
\hline Genotype & 28 & 32.3 & $14.5 * * *$ & 198 & 15.5 & $3.4 * * *$ & 11 & 0.5 & $1.4 \mathrm{~ns}$ & 18 & 13.0 & $3.1 * *$ \\
\hline Isolate & 3 & 24.4 & $22.4 * * *$ & $\ldots$ & $\ldots$ & $\ldots$ & 3 & 2.7 & $2.5 \mathrm{~ns}$ & 3 & 4.4 & $2.1 \mathrm{~ns}$ \\
\hline Genotype $\times$ isolate & 84 & 1.5 & $1.5 * * *$ & $\ldots$ & $\ldots$ & $\ldots$ & 33 & 0.3 & $1.4 \mathrm{~ns}$ & 54 & 1.2 & $1.6 *$ \\
\hline Genotype $\times$ run & 56 & 2.2 & $2.5 * * *$ & 387 & 4.4 & $3.9 * * *$ & 22 & 1.2 & $4.7 * * *$ & 36 & 4.2 & $5.6 * * *$ \\
\hline Isolate $\times$ run & 6 & 1.0 & $1.2 \mathrm{~ns}$ & $\ldots$ & $\ldots$ & $\ldots$ & 6 & 1.1 & $4.2 * * *$ & 6 & 2.0 & $2.7 *$ \\
\hline Genotype $\times$ isolate $\times$ run & 165 & 0.8 & $5.1 * * *$ & $\cdots$ & $\cdots$ & $\ldots$ & 31 & 0.2 & $2.6 * * *$ & 105 & 0.7 & $3.6 * * *$ \\
\hline
\end{tabular}

a Experiment I, evaluation of 29 well-known cultivars against four isolates; experiment II, evaluation of 199 core collection accessions against the isolate 2; experiment III, evaluation of 11 highly resistant core collection accessions from experiment I against four isolates; and experiment IV, long-term evaluation of 19 materials selected from the experiments II and III against four isolates; *, **, and *** indicate $P<0.05,0.01$, and 0.001 , respectively; ns $=$ not significant. 
in the greenhouse straw test. The line G122 and cv. Tendergreen were also included in this test. The ANOVA revealed significant differences for genotype and all interactions (Table 2; experiment IV). The average correlation among genotypic means among the three runs was low $(r=$ $0.149, P<0.05$ ), once again indicating the need for multiple runs to adequately determine genotypic response to white mold using the straw test.

In all cases, materials with a high level of resistance in the short-term tests had more severe reactions in the longer-term inoculation test (Table 6). Line G122, an important source of partial resistance, was the most susceptible genotype in this test, which further attests to the severity of longer-term evaluation. Considering the mean reactions against the four isolates, 15 genotypes exhibited significantly less susceptibility than G122 (Table 6). Line AB136 with intermediate reaction was the only line to maintain the same level of response for both short- and long-term inoculations. For AB136 and accessions BGE003121,

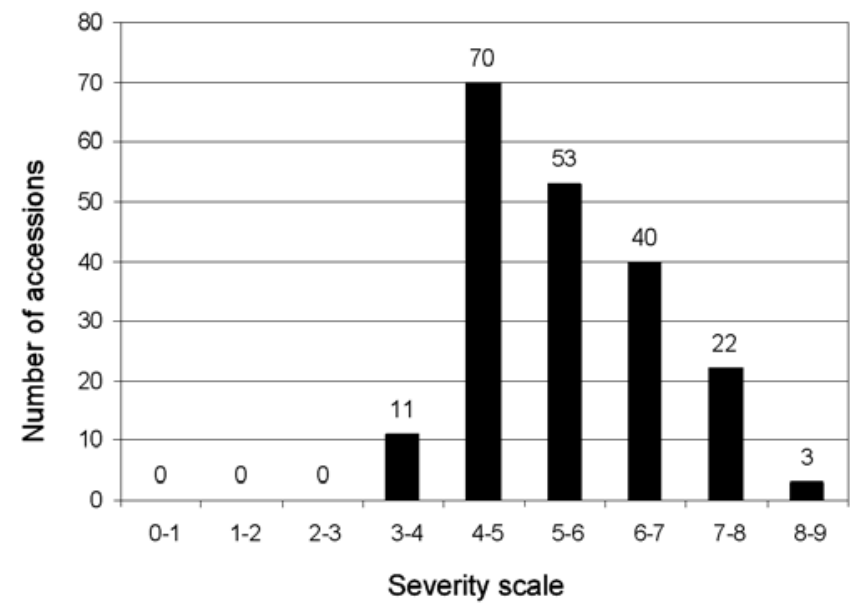

Fig. 1. Distribution of the reaction to Sclerotinia sclerotiorum isolate 2 for 199 bean accessions included in the core collection established from the National Spanish bean collection (Center for Plant Genetic Resources, Alcalá de Henares, Madrid, Spain) using the greenhouse straw test screening method and a 1 -to- 9 disease severity scale, where $1=$ no visible symptoms and $9=$ total plant collapse. greater than the resistance source G122 under more severe, long-term evaluations in the greenhouse straw test. However, when these genotypes were maintained for 21 days, an advance of the disease in the inoculated stem was generally observed. Terán and Singh (31) also observed disease progression when plants were assessed 16 , 23 , or 33 days after the inoculation. Differences between the response in the shortand long-term evaluations could be due to an avoidance mechanism such as the internode length. Using the straw test, Miklas et al. (15) observed a significant correlation between the first internode length and the disease response of the plant. Longerterm evaluations are recommended to confirm reactions for genotypes with high resistance levels in the short-term evaluations.

The high level of resistance in A195 developed by Singh et al. (27) was confirmed in this study. Accession BGE022494 has the best potential for culinary use as a snap bean and should be useful for the improvement of such materials. Interestingly, the core mapping parents BAT93/Jalo EEP558 differed significantly for disease reaction, suggesting that the $\mathrm{BJ}$ recombinant inbred line (RIL) population could be useful for detecting QTL conditioning white mold response.

All of these newly identified putative sources of white mold resistance, with the exception of AB136 which is from the Middle American gene pool, are of Andean origin. Of the 199 accessions in the core collection, $73 \%$ are of Andean origin (22); therefore, identification of resistance in the collection solely from the Andean gene pool is not surprising. However, most of the previously discovered resistance sources are Andean, too, which begins to suggest that natural selection for resistance to this pathogen has been more prominent in the Andean versus Middle American gene pool.

Bunsi navy bean is the only well-known source of white mold resistance discovered

Table 4. Main morphological traits of the 11 accessions included in the CRF core collection which were resistant to the isolate 2 in experiment II

\begin{tabular}{|c|c|c|c|c|c|c|c|c|c|c|c|}
\hline $\begin{array}{l}\text { Accession } \\
\text { no. }\end{array}$ & Market class & $\begin{array}{l}\text { Coat } \\
\text { color }^{\text {a }}\end{array}$ & $\begin{array}{c}\text { Coat } \\
\text { patterns }\end{array}$ & $\begin{array}{c}\text { Growth } \\
\text { habit }\end{array}$ & Shape & $\begin{array}{l}\text { Cross- } \\
\text { section }\end{array}$ & Size $^{b}$ & Snap $^{c}$ & $\begin{array}{c}\text { Second } \\
\text { internode } \\
\text { length }\end{array}$ & $\begin{array}{c}\text { Phaseolin } \\
\text { type }\end{array}$ & Gene pool $^{\mathrm{d}}$ \\
\hline BGE003121 & Brown marrow & br & Absent & IV & Oval & Oval & Medium & Yes & Short & $\mathrm{C}$ & Andean \\
\hline BGE003254 & Dorado & $\mathrm{y}$ & Absent & III & Oblong & Oval & Large & No & Medium & $\mathrm{T}$ & Andean \\
\hline BGE003404 & Marrow & w & Absent & II & Round & Round & Medium & No & Short & $\mathrm{T}$ & Andean \\
\hline BGE003568 & Bayo gordo & $\mathrm{c}$ & Absent & III & Oval & Round & Large & No & Short & $\mathrm{T}$ & Andean \\
\hline BGE003693 & Marrow & $\mathrm{w}$ & Absent & I & Oval & Round & Medium & No & Short & $\mathrm{T}$ & Andean \\
\hline BGE003997 & $\ldots$ & $\mathrm{w}$ & Absent & IV & Kidney & Flat & Small & Yes & Short & $\mathrm{C}$ & Middle American \\
\hline BGE004000 & Cranberry & $\mathrm{c}, \mathrm{pu}$ & Striped & IV & Oval & Oval & Medium & Yes & Short & $\mathrm{C}$ & Andean \\
\hline BGE013952 & Rounded caparron & $\mathrm{w}, \mathrm{c}, \mathrm{pu}$ & Bicolor & IV & Oval & Round & Medium & No & Long & $\mathrm{C}$ & Andean \\
\hline BGE013953 & Sangretoro & $\mathrm{pu}$ & Absent & IV & Oval & Oval & Medium & No & Short & $\mathrm{C}$ & Andean \\
\hline BGE022494 & Brown marrow & $\mathrm{br}$ & Absent & IV & Oval & Oval & Medium & No & Long & $\mathrm{C}$ & Andean \\
\hline BGE026166 & $\ldots$ & br & Absent & IV & Kidney & Round & Large & No & Long & $\mathrm{C}$ & Andean \\
\hline
\end{tabular}

a Seed color: primary, secondary, and tertiary color designations (separated by a comma) as $\mathrm{w}=$ white, $\mathrm{c}=\mathrm{cream}, \mathrm{y}=$ yellow, $\mathrm{br}=\mathrm{brown}, \mathrm{pu}=\mathrm{purple}$, and $\mathrm{g}$ = gray.

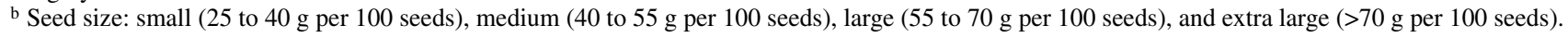

${ }^{c}$ Potential culinary use as snap bean.

d Based on the unweighted pair group method with arithmetic means dendrogram described by Pérez-Vega et al. (22). 
from the Middle American gene pool (9,17). A few dry bean lines (I9365-31, 92BG-7, and I9365-25) purported to possess white mold resistance introgressed from $P$. coccineus could be classified as Middle American (16); however, the actual origin of the resistance in these lines is not fully understood. Given that few resistance sources are of Middle American origin, the identification of another putative source of resistance, $\mathrm{AB} 136$, from this gene pool is a

Other researchers $(15,24)$ conducting straw tests in bean and pea (Pisum sativa L.) noted that, for some genetic populations, plants with longer internodes had lower disease scores, which suggests the influence of morphology on disease reaction. In this study, the accessions with the highest levels of resistance had short internodes (Table 4), indicating that physiological mechanisms primarily conditioned the resistance response. Porter et al. (24) mentioned that white-mold-resistant pea significant finding.

genotypes should combine internodal resistance with nodal resistance that inhibits lesion expansion down the stem. Disease progression for common bean is similarly stalled at the second or third node, with new shoots often developing at these nodes in resistant materials, as observed in this study.

Significant differences for aggressiveness among the four $S$. sclerotiorum isolates was detected in experiment I only, maybe due to the wider and nonselected diversity included in this bean set. Generally, isolates 1 and 3 were slightly more aggressive than isolate 4 but, overall, the results indicate that any of the four isolates could be used effectively to differentiate white mold reaction among common bean in the greenhouse straw test. Nonetheless, noted variation in the aggressiveness of $S$. sclerotiorum warrants characterization of collected isolates before using them for routine screening work. Differences in aggressiveness among $S$. sclerotiorum

Table 5. Short-term responses of 11 common bean accessions included in the CRF core collection inoculated with four Sclerotinia sclerotiorum isolates from northern Spain using the greenhouse straw method (experiment III)

\begin{tabular}{lccccc}
\hline & \multicolumn{5}{c}{ Mean } \\
\cline { 2 - 6 } Accession no. & Isolate 1 & Isolate 2 & Isolate 3 & Isolate 4 & Accession \\
\hline BGE022494 & 3.36 & 3.91 & 3.79 & 3.67 & 3.68 \\
BGE003254 & 4.16 & 3.37 & 3.96 & 3.35 & 3.71 \\
BGE003404 & 3.93 & 3.32 & 3.83 & 3.85 & 3.73 \\
BGE003121 & 4.00 & 3.50 & 3.75 & 3.87 & 3.78 \\
BGE013953 & 3.95 & 3.79 & 3.54 & 3.91 & 3.80 \\
BGE003693 & 3.56 & 3.73 & 3.97 & 4.16 & 3.86 \\
BGE003997 & 3.87 & 4.00 & 3.77 & 3.72 & 3.87 \\
BGE013952 & 4.02 & 3.86 & 3.77 & 3.95 & 3.91 \\
BGE004000 & 3.87 & 3.80 & 4.37 & 3.62 & 3.92 \\
BGE003568 & 4.67 & 3.43 & 3.83 & 4.35 & 4.07 \\
BGE026166 & 4.37 & 3.75 & 4.06 & 4.16 & 4.08 \\
G122 & 4.80 & 4.54 & 4.75 & 4.43 & 4.63 \\
Isolate mean & 4.05 & 3.76 & 3.95 & 3.92 & $\ldots$ \\
\hline
\end{tabular}

Table 6. Long-term responses of 19 common bean materials against four local isolates of Sclerotinia sclerotiorum considering the disease progress in the inoculated stems (experiment IV)

\begin{tabular}{lccccc}
\hline & \multicolumn{5}{c}{ Mean } \\
\cline { 2 - 5 } Genotype & Isolate 1 & Isolate 2 & Isolate 3 & Isolate 4 & Genotype \\
\hline BGE003121 & 5.68 & 5.29 & 6.90 & 5.90 & 5.94 \\
AB136 & 5.73 & 6.44 & 6.52 & 5.87. & 6.14 \\
BGE003254 & 6.48 & 6.54 & 6.41 & 5.99 & 6.35 \\
BGE022494 & 5.61 & 6.97 & 6.60 & 6.25 & 6.35 \\
BGE003568 & 6.70 & 6.40 & 7.57 & 6.35 & 6.76 \\
Kaboon & 7.44 & 6.20 & 6.98 & 6.46 & 6.77 \\
BGE026166 & 7.06 & 6.76 & 7.15 & 6.27 & 6.81 \\
BRB57 & 6.51 & 7.25 & 7.07 & 6.41 & 6.81 \\
BGE003997 & 6.80 & 6.87 & 6.94 & 6.60 & 6.81 \\
BGE013953 & 6.74 & 7.25 & 7.03 & 7.09 & 7.03 \\
BRB130 & 7.18 & 7.79 & 7.09 & 6.67 & 7.18 \\
Don Timoteo & 6.90 & 7.61 & 7.63 & 7.45 & 7.40 \\
A195 & 7.94 & 7.44 & 7.49 & 6.92 & 7.45 \\
BGE004000 & 8.05 & 7.48 & 7.63 & 7.37 & 7.63 \\
BGE003693 & 7.79 & 7.26 & 8.34 & 7.85 & 7.81 \\
BGE003404 & 8.94 & 7.77 & 8.17 & 7.19 & 8.02 \\
BGE013952 & 8.50 & 7.96 & 8.21 & 8.03 & 8.17 \\
Tendergreen & 8.70 & 7.81 & 8.13 & 8.38 & 8.26 \\
G122 & 8.55 & 8.42 & 8.76 & 7.70 & 8.36 \\
Isolate mean & 7.23 & 7.13 & 7.40 & 6.88 & $\ldots$ \\
LSD (0.05) ${ }^{\mathrm{a}}$ & $\ldots$ & $\ldots$ & $\ldots$ & $\ldots$ & 0.53 \\
\hline Least & $\ldots$ & & & $\ldots$ \\
\end{tabular}

a Least significant differences value (5\%) for genotype-isolate mean comparisons $=0.63$. isolates has been previously described $(10,21)$.

The isolate-genotype interactions detected in experiments I and IV seem to result more from the noted differences in aggressiveness among the isolates than due to a true host-pathogen differential interaction. For instance, many genotypes with susceptible ratings to the more-aggressive isolates 1 and 3 exhibited intermediate reactions to the least-aggressive isolate 4 . Only one genotype, Cornell 606, varied widely in response across the isolates, ranging in reaction from 6.1 to 3.9. Other genotypes, such as PC 50 and PI 207262, also varied in response across the isolates. These three genotypes and perhaps a few others may be useful for pathogenic characterization of the $S$. sclerotiorum isolates. Park et al. (21) tested a PC 50/XAN 159 RIL population for reaction to two $S$. sclerotiorum isolates and detected QTL that conditioned resistance to both isolates but also QTL that were isolate specific. However, clear pathogen-host specificity for white mold disease in common bean has not been validated in this or previous studies.

The straw test is an aggressive method favoring infection because pathogen entry into the plant is provided by cutting the main stem and an initial nutrient source is provided by the agar plug. These favorable conditions are not common in the field; nonetheless, good correlations between straw tests and field trials have been observed $(8,11,14,21)$. The logical next step for the resistant materials identified in this study will be to field test them for white mold reaction and to study the inheritance of resistance for both greenhouse and field environments.

\section{ACKNOWLEDGMENTS}

This work was supported by grants AGL200766563-C02-02 from the Ministerio de Ciencia y Tecnología, Spain. A. Pascual was recipient of a salary fellowship from the Caja Rural de Gijón (Spain) and E. Pérez-Vega was recipient of a salary fellowship from the Instituto Nacional de Investigación y Tecnología Agraria y Alimentaria (INIA, Spain).

\section{LITERATURE CITED}

1. Chung, Y. S., Sass, M. E., and Nienhuis, J. 2008. Validation of RAPD markers for white mold resistance in two snap bean populations based on field and greenhouse evaluations. Crop Sci. 8:2265-2275.

2. Ender, M., and Kelly, J. D. 2005.Identification of QTL associated with white mold resistance in common bean. Crop Sci. 45:2482-2490.

3. Ender, M., Terpstra, K., and Kelly, J. D. 2008. Marker-assisted selection for white mold resistance in common bean. Mol. Breed. 21:149157.

4. Freyre, R., Skroch, P. W., Geffroy, V., AdamBlondon, A. F., Shirmohamadali, A., Johnson, W. C., Llaca, V., Nodari, R. O., Pereira, P. A., Tsai, S. M., Tohme, J., Dron, M., Nienhuis, J., Vallejos, C. E., and Gepts, P. 1998. Towards an integrated linkage map of common bean. 4 . Development of a core linkage map and alignment of RFLP maps. Theor. Appl. Genet. 97:847-856. 
5. Gepts, P., Osborn, T. C., Rashka, K., and Bliss, F. A. 1986. Phaseolin-protein variability in wild forms and landraces of the common bean (Phaseolus vulgaris): evidence for multiple centers of domestication. Econ. Bot. 40:451468.

6. Griffiths, P. D. 2009. Release of Cornell 601606: common bean breeding lines with resistance to white mold. HortScience 44:463465.

7. Hall, R., and Nasser, L. C. B. 1996. Practice and precept in cultural management of bean diseases. Can. J. Plant Pathol. 18:176-185.

8. Hall, R., and Phillips, L. G. 1997. Resistance to white bean to white mold: field evaluations of straw test. Annu. Rep. Bean Improv. Coop. 40:138-139.

9. Kolkman, J. M., and Kelly, J. D. 2003. QTL conferring resistance and avoidance to white mold in common bean. Crop Sci. 43:539-548.

10. Kull, L.S., Pedersen, W. L., Palmquist, D., and Hartman, G. L. 2004. Mycelial compatibility grouping and aggressiveness of Sclerotinia sclerotiorum. Plant Dis. 88:325-332.

11. Maxwell, J. J., Brick, M. A., Byrne, P. F., Schwartz, H. F., Shan, X., Ogg J. B., and Hensen, R. A. 2007. Quantitative trait loci linked to white mold resistance in common bean. Crop Sci. 47:2285-2294.

12. Miklas, P. N. 2007 Marker-assisted backcrossing QTL for partial resistance to Sclerotinia white mold in dry bean. Crop Sci. 47:935-942.

13. Miklas, P. N., Delorme, R., Hannan, R., and Dickson, M. H. 1999. Using a subsample of the core collection to identify new sources of resistance to white mold in common bean. Crop Sci. 39:569-573.

14. Miklas, P. N., Delorme, R., Johnson, W. C., and Gepts, P. 2001. QTL conditioning physiological resistance and avoidance to white mold in dry bean. Crop Sci. 41:309-315.

15. Miklas, P. N., Delorme, R., and Riley R. 2003. Identification of QTL conditioning resistance to white mold in snap bean. J. Am. Soc. Hortic. Sci. 128:564-570.

16. Miklas, P. N., Grafton, K. F., Kelly, J. D., Schwartz, H. F., and Steadman, J. R. 1998. Registration of four white mold resistant dry bean germplasm lines: I9365-3, I9365-5, I9365-31, and 92BG-7. Crop Sci. 38:1728.

17. Miklas, P. N., Hauf, D., Henson, R., and Grafton, K. F. 2004. Inheritance of ICA Bunsiderived resistance in a navy $\times$ pinto bean cross. Crop Sci. 44:1584-1588.

18. Miklas, P. N., Larsen, K. M., Terpstra, K. A., Hauf, D. C., Grafton, K. F., and Kelly, J. D. 2007. QTL analysis of ICA Bunsi-derived resistance to white mold in a pinto $\times$ navy bean cross. Crop Sci. 47:174-179.

19. Miklas, P. N., Soule, M., Porter, L., Blair, M 2009. Comprehensive QTL linkage map for resistance to Sclerotinia white mold in common bean. (Abstr.) Phytopathology 99:S86.

20. Pastor-Corrales, M. A 1991. Estandarización de variedades diferenciales y de designación de razas de Colletotrichum lindemuthianum. (Abstr.) Phytopathology 81:694.

21. Park, S. O., Coyne, D. P., Steadman, J. R., and Skroch, P. W. 2001 Mapping of QTL for resistance to white mold disease in common bean. Crop Sci. 41:1253-1262.

22. Pérez-Vega, E., Campa, A., De la Rosa, L., Giraldez, R., and Ferreira, J. J. 2009. Genetic diversity in a core collection established from the main bean genebank in Spain. Crop Sci. 49:1377-1386.

23. Petzoldt, R., and Dickson, M. H. 1996. Straw test for resistance to white mold in beans. Annu. Rep. Bean Improv. Coop. 39:142-143.

24. Porter, L. D., Hoheisel, G., and Coffman, V. A 2009. Resistance of peas to Sclerotinia sclerotiorum in the Pisum core collection. Plant Pathol. 58:52-60.

25. Santalla, M., Rodino, A. P., and De Ron, A. M. 2002. Allozyme evidence supporting southwestern Europe as a secondary center of genetic diversity for common bean. Theor. Appl. Genet. 104:934-944

26. Schwartz, H. F., Casciano, D. H., Asenga, J. A., and Wood, D. R. 1987. Field measurement of white mold effects upon dry beans with genetic resistance or upright architecture. Crop Sci. 27:699-702.

27. Singh, S. P., Terán, H., Lema, M., Schwartz, H F., and Miklas, P. N. 2007 Registration of white mold resistant dry bean germplasm line A 195. J. Plant Regist. 1:62-63.

28. Singh, S. P., Terán, H., Schwartz, H. F., Otto, K., and Lema, M. 2009. Introgressing white mold resistance from Phaseolus species of the secondary gene pool into common bean. Crop Sci. 49:1629-1637.

29. Steadman, J. R. 1983. White mold: a serious yield-limiting disease of bean. Plant Dis. 67:346-350.

30. Steadman, J. R., Eskridge, K., Costa, J., Grafton, K., Kelly, J. D., Kmiecik, K., Kolkman, J. Myers, J., and Miklas, P. 2001. Evaluation of sources of resistance to Sclerotinia sclerotiorum in common bean with five test methods and multiple locations. Annu. Rep. Bean Improv. Coop. 49:115-116.

31. Terán, H., and Singh, S. P. 2009. Gamete selection for improving physiological resistance to white mold in common bean Euphytica 167:271-280. 